OPEN ACCESS

Edited by:

Shane Andrew Thomas,

Shenzhen International

Primary Health Care

Research Institute, China

Reviewed by:

Alun Conrad Jackson,

Australian Centre for

Heart Health, Australia

Jeff Bolles,

University of Mount Olive,

United States

*Correspondence:

Tai Hing Lam

hrmrlth@hku.hk

Specialty section:

This article was submitted to Public Health Education and Promotion,

a section of the journal

Frontiers in Public Health

Received: 30 June 2017 Accepted: 11 September 2017 Published: 29 September 2017

Citation:

Shen C, Wan A, Kwok LT, Pang S, Wang $X$, Stewart SM, Lam TH and

Chan SSC (2017) A Community-

Based Intervention Program to Enhance Family

Communication and Family Well-being: The Learning Families Project in Hong Kong.

Front. Public Health 5:257.

doi: 10.3389/fpubh.2017.00257

\section{A Community-Based Intervention Program to Enhance Family Communication and Family Well-being: The Learning Families Project in Hong Kong}

\author{
Chen Shen ${ }^{1}$, Alice Wan', Lit Tung Kwok², Sally Pang ${ }^{2}$, Xin Wang ${ }^{1}$, Sunita M. Stewart ${ }^{3}$, \\ Tai Hing Lam ${ }^{1 *}$ and Sophia Siu Chee Chan ${ }^{4}$
}

${ }^{1}$ Li Ka Shing Faculty of Medicine, School of Public Health, The University of Hong Kong, Hong Kong, Hong Kong, ${ }^{2}$ Christian Family Service Center, Kwun Tong, Hong Kong, ${ }^{3}$ Department of Psychiatry, The University of Texas Southwestern Medical Center at Dallas, Dallas, TX, United States, ${ }^{4}$ Li Ka Shing Faculty of Medicine, School of Nursing, The University of Hong Kong, Hong Kong, Hong Kong

Background: Family communication is important to maintain family relationships and family well-being. To enhance family communication and family well-being, a community-based "Learning Families Project," based on the social ecological model was developed in Kwun Tong in Hong Kong, a district with high prevalence of family problems.

Methods: This quasi-experimental study included two nearby government subsidized low-rent housing estates separated by busy main roads, as the intervention [Tsui Ping (South) Estate] and control (Shun Tin Estate) estate. The main intervention was resident training programs, such as talks, day camps, and thematic activities. No program was implemented in the control estate. Participants in the intervention group received assessments before the intervention (T1), immediately after the intervention (T2), and 6 weeks after the intervention (T3). Control group participants were assessed at baseline (March to April 2011) and follow-up (December 2011 to March 2012). Assessments of family communication (time and perceived adequacy) and family well-being (harmony, happiness, and health) at T1 and T3 were obtained in the intervention group to examine within-group changes. In addition, these differences in outcomes in the intervention group were compared with those in the control group to examine the effectiveness of the intervention.

Results: Family communication time and perceived communication adequacy increased significantly in the intervention group $(n=515)$ with a small effect size (Cohen effect $d$ : 0.10 and 0.24 , respectively). Compared with the control group $(n=476)$, the improvements in family communication time and perceived communication adequacy (Cohen effect $d: 0.13$ and 0.14 , respectively), and perceived family harmony and happiness (Cohen effect $d$ : 0.12 and 0.12 , respectively) were significantly greater in the intervention group, adjusting for age and education, suggesting the intervention was 
effective in improving family communication and family well-being. Mediation analysis showed that perceived communication adequacy mediated the effects of the intervention on family harmony $[\beta=0.10,95 \%$ confidence interval $(\mathrm{Cl}) 0.03,0.18]$, happiness ( $\beta=0.12,95 \% \mathrm{Cl} 0.04,0.20)$, and health $(\beta=0.10,95 \% \mathrm{Cl} 0.02,0.17)$, adjusting for age and education.

Conclusion: This community intervention based on the social ecological model improved family well-being through improving family communication, which could be an effective target to promote family well-being in other communities.

Trial registration: This study was registered under ClinicalTrials.gov, identifier NCT02851667. URL: https://clinicaltrials.gov/ct2/show/NCT02851667?term=02851667 \&rank=1.

Keywords: community-based intervention, community engagement, family, social ecological model, mediation analysis

\section{INTRODUCTION}

Family well-being, which has been conceptualized as "familylife satisfaction," "sense of well-being," and "family function" (1), is associated with outcomes such as hypertension, selfrated health, depression, and self-esteem in family members (2-5). Inter-personal harmony in the family is believed to be crucial for the Chinese who see it as contributing not only to each individual member's welfare but also to a well-organized and peaceful world $(6,7)$. According to traditional Confucius ideals, family harmony is the basis for an individual's happiness (8). Our qualitative studies in Hong Kong have also found that family health, happiness, and harmony $(3 \mathrm{Hs})$ are three major themes of family well-being $(9,10)$. Family health includes physical and mental health of family members, which is strongly related to psychological capital and family unity (9). Family happiness can be enhanced by spending time with family members and building connection with friends and relatives. Family harmony means absence of conflicts and effective communication with family members. Forbearance and spending time with family are important in forming a harmonious family (9).

Family communication is important for maintaining family well-being because it provides the foundations of a symbolic, transactional process of creating and sharing meanings, thoughts, feelings or ideas for family members as well as seeking satisfaction (11-13). High-quality communication in family has been reported as one dimension of family well-being (14). In addition, communication, especially non-confrontational and mutually supportive communication (harmony) is a way to develop and maintain inter-personal relationships within the members in their social networks such as the family $(15,16)$.

Kwun Tong is a district in Hong Kong with a high prevalence of family problems such as elderly abuse, domestic violence, and child abuse $(17,18)$. In order to promote family $3 \mathrm{Hs}$ or well-being in Kwun Tong, the "Learning Families Project (LFP)" was delivered with a series of community-based intervention programs. The LFP was part of the project entitled "FAMILY: a Jockey Club Initiative for a Harmonious Society" (the FAMILY Project) that included a longitudinal family cohort study (19), other interventional studies (20-23), and social marketing programs (24). The FAMILY project focused on the family as a unit and aimed to identify the sources of family problems, devise appropriate preventive measures, and promote family $3 \mathrm{Hs}$.

The LFP was initiated based on the social ecological model. This social ecological model proposes dynamic interrelations among various personal and environmental factors (25). The model emphasizes people's behaviors are affected by intrapersonal, inter-personal, community, and societal factors (26). These programs promoted the concepts of Learning Family and family $3 \mathrm{Hs}$ to the participants (intra- and inter-personal level), and was innovative in extending across multiple levels of factors. The concepts of Learning Family indicated that family relationship could be improved when family members participate in learning activities together. These programs also provided a platform for family members to learn together and communicate with each other (inter-personal level), as well as for residents to interact in these community activities (community level).

Previous intervention programs using the social ecological model have required intensive involvement from both the service providers and recipients $(27,28)$, perhaps making such kind of programs difficult to sustain and disseminate. Our previous brief community-based intervention programs, often with a core session and booster session, yielded some small but significant improvement on family communication, parentchild relationships, and family well-being $(29,30)$. In addition, previous studies on family communication mainly focused on communication patterns, rather than communication time or adequacy (31-33). Our previous telephone survey in Hong Kong showed face-to-face and phone use for family communication associated with a higher level of perceived family well-being (34). This study aimed to examine whether our brief community-based intervention programs could improve family communication and family well-being. We also examined the contribution of family communication by mediation analysis (35), including family communication time and perceived 


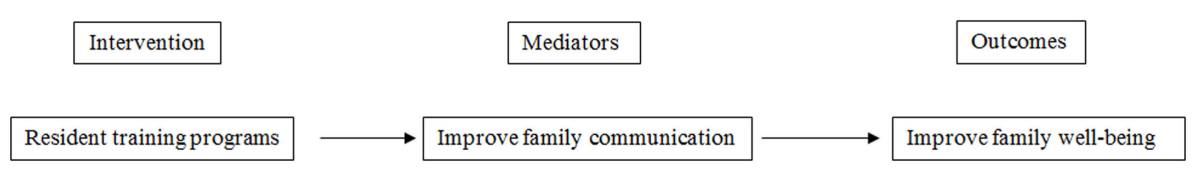

FIGURE 1 | Pathway of intervention on outcomes.

communication adequacy to the improvement in family wellbeing. The pathway of the intervention on outcomes is shown in Figure 1.

\section{MATERIALS AND METHODS}

\section{Participants}

Participants were recruited by a large charitable non-governmental social welfare organization, Christian Family Service Center (CFSC), with the mission to support and enhance family functioning and to foster an environment for growth and change in this district. CFSC provides an array of services such as children and family services, youth services, and elderly care services (36). CFSC initiated the Learning Family approach and collaborated with School of Public Health, The University of Hong Kong (HKU) in planning and implementing LFP.

We chose Tsui Ping (South) Estate as the intervention estate, and Shun Tin Estate as the control estate. As the two estates offer government subsidized, public, and low-rent housing, the residents are of similar socio-economic backgrounds. They are located about $2.6 \mathrm{~km}$ apart, and are well-separated by busy main roads, minimizing the likelihood of cross-social relationships and transfer. Residents living in the designated estates were eligible if they were Hong Kong residents, older than 10 years of age, and could communicate in Chinese (Cantonese or Putonghua). The headquarter of CFSC is located at a few minutes' walk from Tsui Ping (South) Estate.

Key community stakeholders such as the Estate Management Advisory Committees (EMAC) and the Mutual Aid Committees (MAC) in the intervention estate were actively engaged as key partners in this study, including joining focus group interviews at the needs assessment stage. The needs assessment was conducted to explore their views on how to promote family $3 \mathrm{Hs}$ in Kwun Tong families as well as learning needs, resources, and feasibility of this study. A train-the-trainer program was designed and implemented from December 2010 to February 2011 by HKU and CFSC to engage and equip resident leaders from both EMAC and MAC to recruit participants and organize family programs with the Learning Family concepts and leadership skills. Intervention programs included promotion programs, resident training programs, and learning programs. This paper focuses on resident training programs, which were the main intervention of the LFP.

Fieldwork recruitment of residents took place from March to December 2011. A diverse array of recruitment strategies were used concurrently, including posters, leaflets, and banners, a kick-off ceremony, promotion activities, telephone calls, mobile counter, and door-to-door canvassing to raise awareness of the
LFP in the community residents. Resident leaders, CFSC project staff (social workers), and HKU academic staff, were actively involved in the recruitment process.

\section{Intervention Development}

Based on the information from the needs assessment, 24 resident training programs such as talks, day camp, and thematic activities were delivered in the intervention estate by CFSC from June to November 2011. Each program included an introduction to the concepts of Learning Family and family $3 \mathrm{Hs}$ as well as how to promote family $3 \mathrm{Hs}$ through learning and communicating with family, delivered by interactive games and workshops. The workshops included a variety of topics such as cooking and handwork, enabling family members to learn, and communicate with each other. Resident training programs except for the day camp were held in CFSC headquarters with the duration limited to $2 \mathrm{~h}$ to enhance recruitment and reduce costs. The day camp was held in a holiday camp and the duration of contents related to learning family in day camps was also limited to $2 \mathrm{~h}$. Participants completed a questionnaire before (T1) and immediately after the intervention (T2). A 26-page booklet (Learning Family Booklet) produced as a tool for training and also used as a record book for the participants to document their participation in the learning activities as well as their learning contents, was distributed to each participant. The number of participants in the resident training programs was 980, with 515 valid questionnaires at $\mathrm{T} 1$ and 444 valid questionnaires at $\mathrm{T} 2$.

A total of six booster sessions were held 6 weeks after the resident training programs for the participants in the New Life Interactive Farm from July to December 2011. The duration of each session was $3 \mathrm{~h}$. Each participant in the booster session had attended one resident training program and had completed a valid questionnaire at T1. The participants had a guided tour of the farm and two experiential activities (organic farming and seed learning). Debriefing and reviews of the concepts of Learning Family and family $3 \mathrm{Hs}$ were also provided. Questionnaire assessment was conducted after the booster session (T3). The number of participants in the booster session was 365 , with 345 valid questionnaires at T3. Each participant with a valid questionnaire at $\mathrm{T} 3$ received one resident training program and one booster session. The flow diagram of the intervention is presented in Figure 2.

\section{Baseline and Follow-up Surveys}

We conducted a baseline (before the intervention programs) and a follow-up survey (after the end of intervention programs) in the intervention and control estates using a self-administrated questionnaire in order to evaluate the whole impact of the 


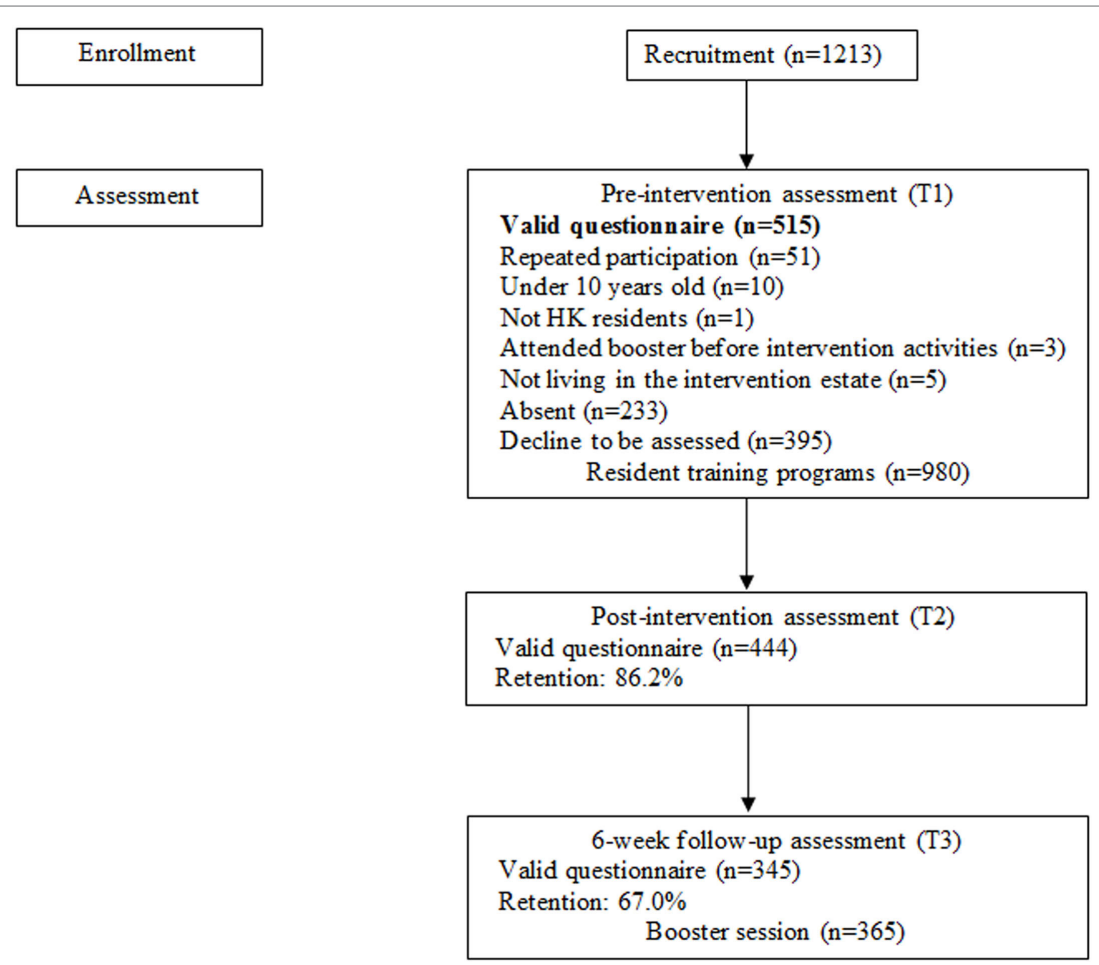

No program was implemented in the control estate

FIGURE 2 | The flow diagram of participants in the intervention group.

programs on the community. The questionnaires were delivered and collected by multiple methods such as mobile counters, security desk in housing blocks, door-to-door visits, and street booths.

A total of 1,167 and 1,108 residents in the intervention and control estates, respectively, participated in the baseline survey, and 1,323 and 1,108 residents in the intervention and control estates, respectively, participated in the follow-up survey. A total of 502 and 476 residents from the intervention and control estate, respectively, were successfully followed up (the same person completed both the baseline and follow-up questionnaires) using record linkage based on the name and residential address. The baseline survey was conducted from March to April 2011, and the follow-up survey was conducted from December 2011 to March 2012.

\section{Focus Group Interview}

Six focus group interviews were conducted with 54 participants who had participated in the resident training programs to explore their experiences in the programs, their mastery of Learning Family concepts, as well as the changes in family communication and family $3 \mathrm{Hs}$. The number of participants in each focus group ranged from 6 to 12 .

These interviews were conducted from February to May 2012 in a quiet venue (e.g., an activity room) and lasted about $60 \mathrm{~min}$. Each group was managed by a panel of three members, which consisted of one moderator and two note-takers.

\section{Outcomes}

We used family communication time and perceived communication adequacy as measures of family communication. Participants were asked about their average daily communication time (minutes) with family members in the last 7 days. Perceived communication adequacy was measured by asking the participants whether they felt they had adequate communication with family members. Choices included "not adequate at all," "not adequate," "fair," "adequate," and "very adequate." It was measured at T1 and T3 in the intervention group, as well as at baseline and follow-up in the control group. Family $3 \mathrm{Hs}$ were assessed by three separate questions which have been used in our previous study (34). Respondents provided a score from 0 to 10 for their perceptions of the health, happiness, and harmony in their own families. We used the information on perceived family $3 \mathrm{Hs}$ measured at T1 and T3 in the intervention group, as well as baseline and follow-up in the control group. Family communication and family well-being were not measured at T2 because these cannot change immediately after the intervention.

\section{Assessments}

Participants in the intervention group who received assessments from T1 to T3 $(n=515)$ and respondents who participated in baseline and follow-up surveys in the control group $(n=476)$ were included in the present data analyses. Outcome changes within the intervention group, and comparisons with those in the control group (between group differences in the changes) 
were assessed to examine the effectiveness of the intervention on family communication and family well-being.

\section{Fidelity Check}

Fidelity of the interventions was monitored by HKU academic and CFSC staff. It included program quality and program objectives achievement, both of which were rated on a single item for adherence to program content, with a score scale ranging from 0 to 100. Fidelity checks showed that the mean scores of both program quality and program objectives achievement were more than 75 , indicating that the interventions were delivered to participants successfully as planned.

\section{Ethical Statement}

Ethical approval was granted by the Institutional Review Board (IRB) of the University of Hong Kong/Hospital Authority Hong Kong West Cluster on November 2010. Written informed consent was obtained from all participants before the start of the programs. For participants younger than 15, written consent was obtained from the next of kin, caretakers, or guardians on their behalf. This study was registered under ClinicalTrials. gov (NCT02851667). The authors confirm that all ongoing and related trials for this intervention are registered.

\section{Statistical Analyses}

Chi-square tests and analysis of variance (ANOVA) were used to compare baseline characteristics and outcomes between participants in the intervention and control groups. Paired $t$-test was used to assess the mean change of family communication and perceived family $3 \mathrm{Hs}$ in the intervention group. ANOVA was used to assess the difference of mean change of family communication and perceived family $3 \mathrm{Hs}$ between the intervention and control groups. Effect size was measured using Cohen's $d$. A Cohen's $d$ of 0.20 was described as a small effect, 0.50 as a medium effect, and 0.80 or above as a large effect (37).

To identify the relative contribution of family communication, the total effect of the intervention on family $3 \mathrm{Hs}$ was decomposed into the direct effect of the intervention (effect unexplained by family communication) and the indirect effect via family communication. We performed mediation analysis (35) to obtain the indirect effect, direct effect, and the total effect, adjusting for potential confounders when appropriate. Whether effects varied by age or sex was assessed from the significance of interaction terms and the heterogeneity of estimates across strata.

Multiple imputation was used to handle missing values, which were predicted based on a flexible additive regression model with predictive mean matching incorporating intervention, potential confounders, and outcomes (38). We imputed any missing values 20 times and results from the 20 imputed datasets were summarized into single estimated beta coefficients $(\beta)$ with confidence intervals (CIs) and $P$-values adjusted for the missing data uncertainty. All the statistical analyses were conducted using STATA version 13.0.

Qualitative data were independently analyzed by a panel of two researchers independently: one attended the focus group interviews, while the other was absent, an arrangement promoting accuracy as well as objectivity during analysis. The strategy of thematic content analysis was used (39). Each transcript was analyzed sentence by sentence and coded for respondents' meanings. Initial open coding of the data used differing codes, which were then organized into categories and themes.

\section{RESULTS}

Table 1 shows that participants in the intervention group were older and less educated than those in the control group. Otherwise, sex, monthly household income, and marital status were similar. Communication time and perceived communication adequacy were lower in the intervention group than the control group, but perceived family $3 \mathrm{Hs}$ were similar. There were no significant differences in baseline demographic characteristics, mediators or outcomes between those who completed questionnaires at both $\mathrm{T} 1$ and $\mathrm{T} 3$ and those who were lost to follow-up at T3 (all $P$-values larger than 0.05 , data not shown).Table 2 shows that communication time and perceived communication adequacy increased significantly at T3 with a small effect size (Cohen effect $d: 0.10$ and 0.24 , respectively). Perceived family $3 \mathrm{Hs}$ increased at $\mathrm{T} 3$ insignificantly.

Table 3 shows that the improvements in communication time, perceived communication adequacy, family harmony, and

TABLE 1 | Baseline demographic characteristics, mediators, and outcomes between participants in the intervention and control group.

\begin{tabular}{|c|c|c|c|}
\hline & $\begin{array}{c}\text { Intervention } \\
\text { group } \\
(n=515)\end{array}$ & $\begin{array}{l}\text { Control } \\
\text { group } \\
(n=476)\end{array}$ & $P$-values a \\
\hline \multicolumn{4}{|l|}{ Sex (\%) } \\
\hline Men & 27.5 & 29.8 & \\
\hline Women & 72.5 & 70.2 & 0.46 \\
\hline \multicolumn{4}{|l|}{ Age (\%) } \\
\hline$<18$ & 12.2 & 3.4 & \\
\hline $18-44$ & 26.4 & 33.9 & \\
\hline $45-64$ & 25.0 & 32.4 & \\
\hline $65+$ & 36.5 & 30.3 & $<0.001$ \\
\hline \multicolumn{4}{|l|}{ Education level (\%) } \\
\hline No formal education & 20.1 & 14.0 & \\
\hline Primary & 30.9 & 28.8 & \\
\hline Secondary or above & 49.1 & 57.2 & 0.01 \\
\hline \multicolumn{4}{|l|}{ Monthly household income (\%) } \\
\hline$<\mathrm{HK} \$ 4000(\mathrm{US} \$ 1=\mathrm{HK} \$ 7.8)$ & 20.7 & 18.6 & \\
\hline $4,000-7,999$ & 22.2 & 18.8 & \\
\hline $8,000-9,999$ & 16.7 & 18.0 & \\
\hline $10,000-14,999$ & 21.5 & 20.6 & \\
\hline$\geq 15,000$ & 18.9 & 24.0 & 0.46 \\
\hline \multicolumn{4}{|l|}{ Marital status (\%) } \\
\hline Single & 18.2 & 22.5 & \\
\hline Married or cohabitated & 59.0 & 57.9 & \\
\hline Divorced or widowed & 22.8 & 19.6 & 0.18 \\
\hline Communication time $(\min )^{b}$ & $108.7(108.6)$ & 144.5 (139.3) & $<0.001$ \\
\hline $\begin{array}{l}\text { Perceived communication } \\
\text { adequacy }^{b}\end{array}$ & $3.11(0.97)$ & $3.47(0.95)$ & $<0.001$ \\
\hline Family harmony ${ }^{b}$ & $7.50(2.13)$ & $7.71(2.00)$ & 0.13 \\
\hline Family happiness ${ }^{b}$ & $7.29(2.15)$ & $7.28(2.11)$ & 0.96 \\
\hline Family health ${ }^{\mathrm{b}}$ & $7.17(2.10)$ & $7.00(2.08)$ & 0.22 \\
\hline
\end{tabular}

a $P$-values for two-sided $\chi^{2}$ test for demographic characteristics and analysis of variance for mediators and outcomes.

${ }^{b}$ Mean (SD). 
TABLE 2 | The mean change of family communication and family $3 \mathrm{Hs}$ in the intervention group.

\begin{tabular}{|c|c|c|c|c|c|}
\hline & \multicolumn{2}{|c|}{ Mean (SD) } & \multirow{2}{*}{$\begin{array}{l}\text { Mean } \\
\text { change }\end{array}$} & \multirow[t]{2}{*}{$P$-values } & \multirow{2}{*}{$\begin{array}{l}\text { Effect } \\
\text { size }^{a}\end{array}$} \\
\hline & T1 & T3 & & & \\
\hline $\begin{array}{l}\text { Communication } \\
\text { time (min) }\end{array}$ & 108.7 (108.6) & $122.1(119.2)$ & 21.2 & 0.02 & 0.10 \\
\hline $\begin{array}{l}\text { Perceived } \\
\text { communication } \\
\text { adequacy }^{b}\end{array}$ & $3.11(0.97)$ & $3.43(0.88)$ & 0.33 & $<0.001$ & 0.24 \\
\hline Family harmonyc & $7.50(2.13)$ & 7.67 (1.68) & 0.26 & 0.06 & 0.08 \\
\hline Family happiness & $7.29(2.15)$ & $7.43(1.85)$ & 0.16 & 0.18 & 0.06 \\
\hline Family health & 7.17 (2.10) & $7.32(1.91)$ & 0.11 & 0.40 & 0.04 \\
\hline
\end{tabular}

T1, baseline; T3, 6-week follow-up.

$P<0.05$ are marked in bold.

${ }^{a}$ Cohen effect size index $d: 0.20=$ small, $0.50=$ medium, $0.80=$ large.

${ }^{b}$ Scores for perceived communication adequacy ranged from 1 to 5 , with higher scores indicating better outcomes.

'Scores for family harmony, happiness, and health ranged from 0 to 10, with higher scores indicating better outcomes.

TABLE 3 | Differences in changes of family communication and family $3 \mathrm{Hs}$ between the intervention and control group.

\begin{tabular}{|c|c|c|c|c|c|}
\hline & $\begin{array}{l}\text { Intervention } \\
\text { group }\end{array}$ & Control group & F statistic & $P$-values & $\begin{array}{l}\text { Effect } \\
\text { size }^{b}\end{array}$ \\
\hline & $\begin{array}{l}\text { Mean } \\
\text { change }^{a} \\
\text { (T3-T1) }\end{array}$ & $\begin{array}{c}\text { Mean } \\
\text { change (follow } \\
\text { up-baseline) }\end{array}$ & & & \\
\hline $\begin{array}{l}\text { Communication } \\
\text { time (min) }\end{array}$ & 21.2 & -18.0 & 3.87 & 0.01 & 0.13 \\
\hline $\begin{array}{l}\text { Perceived } \\
\text { communication } \\
\text { adequacy }\end{array}$ & 0.33 & 0.02 & 5.12 & 0.002 & 0.14 \\
\hline Family harmony & 0.26 & -0.04 & 3.82 & 0.01 & 0.12 \\
\hline Family happiness & 0.16 & -0.04 & 3.79 & 0.01 & 0.12 \\
\hline Family health & 0.11 & 0.10 & 1.97 & 0.12 & 0.09 \\
\hline
\end{tabular}

T1, baseline; T3, 6-week follow-up.

Adjusted for age and education.

$P<0.05$ are marked in bold.

${ }^{a}$ Positive changes in scores indicated improved outcomes.

${ }^{b}$ Cohen effect size index $\mathrm{d}: 0.20=$ small, $0.50=$ medium, $0.80=$ large.

happiness were significantly greater in the intervention group than the control group, with a small effect size (Cohen effect $d: 0.13,0.14,0.12$, and 0.12 , respectively), after adjusting for age and education. These results suggested effectiveness of the intervention on improving family communication and family well-being.

Table 4 shows that perceived communication adequacy mediated the effect of intervention on perceived family harmony ( $\beta=0.10,95 \%$ CI $0.03,0.18)$, family happiness $(\beta=0.12,95 \%$ CI $0.04,0.20)$, and family health $(\beta=0.10,95 \%$ CI $0.02,0.17)$, adjusted for age and education. However, family communication time showed no mediation effect. All the effects did not vary by age or sex (all $P$-values for interaction larger than 0.05 ).

The improvement in family communication was also found in focus group interviews. The programs provided valuable opportunities for the participants to interact with their family members. They reported that they not only gained an immediate sense of happiness and togetherness during the program activities, family communication also enhanced after that.
TABLE 4 | Adjusted ${ }^{a}$ indirect, direct, and total effect of intervention on family $3 \mathrm{Hs}$ mediated by family communication.

\begin{tabular}{|c|c|c|c|c|c|}
\hline & & \multicolumn{2}{|c|}{$\begin{array}{c}\text { Communication } \\
\text { time }\end{array}$} & \multicolumn{2}{|c|}{$\begin{array}{c}\text { Perceived } \\
\text { communication } \\
\text { adequacy }\end{array}$} \\
\hline & & $\boldsymbol{\beta}$ & $95 \% \mathrm{Cl}$ & $\boldsymbol{\beta}$ & $95 \% \mathrm{Cl}$ \\
\hline \multirow[t]{3}{*}{$\begin{array}{l}\text { Family } \\
\text { harmony }\end{array}$} & $\begin{array}{l}\text { Indirect effect } \\
\text { (with mediator) }\end{array}$ & 0.02 & $-0.01,0.05$ & 0.10 & $0.03,0.18^{\star \star}$ \\
\hline & $\begin{array}{l}\text { Direct effect } \\
\text { (without mediator) }\end{array}$ & 0.30 & $0.01,0.59^{\star}$ & 0.21 & $-0.08,0.51$ \\
\hline & Total effect & 0.32 & $0.02,0.61^{\star}$ & 0.32 & $0.02,0.61^{\star}$ \\
\hline \multirow[t]{3}{*}{$\begin{array}{l}\text { Family } \\
\text { happiness }\end{array}$} & $\begin{array}{l}\text { Indirect effect } \\
\text { (with mediator) }\end{array}$ & 0.02 & $-0.01,0.06$ & 0.12 & $0.04,0.20^{\star *}$ \\
\hline & $\begin{array}{l}\text { Direct effect } \\
\text { (without mediator) }\end{array}$ & 0.26 & $-0.05,0.56$ & 0.16 & $-0.14,0.46$ \\
\hline & Total effect & 0.28 & $-0.03,0.59$ & 0.28 & $-0.03,0.59$ \\
\hline \multirow[t]{3}{*}{$\begin{array}{l}\text { Family } \\
\text { health }\end{array}$} & $\begin{array}{l}\text { Indirect effect } \\
\text { (with mediator) }\end{array}$ & 0.02 & $-0.02,0.06$ & 0.10 & $0.02,0.17^{*}$ \\
\hline & $\begin{array}{l}\text { Direct effect } \\
\text { (without mediator) }\end{array}$ & 0.07 & $-0.26,0.40$ & -0.01 & $-0.33,0.32$ \\
\hline & Total effect & 0.09 & $-0.24,0.42$ & 0.09 & $-0.24,0.42$ \\
\hline
\end{tabular}

$\mathrm{Cl}$, confidence interval.

$P<0.05$ are marked in bold.

${ }^{a}$ Adjust for age and education.

*Statistically significant at $P<0.05$.

**Statistically significant at $P<0.01$.

(I now) spend more time for communicating. He (the child) is busy with his homework. We don't have much time to chat. (Now) I spend more time in knowing more about his study. We (the father and the son) can then be happier. (A father, Group 4, 234Z)

Sometimes when I go back home, I chat with him (my son). In the past, I seldom interacted with him. Now, I initiate the conversation...that means we have an improvement in communication. (A mother, Group $2,272 \mathrm{~A}$ )

In addition to increased time for communication, the participants were also more open to share the happiness and sadness they encountered in daily life.

Now he (the kids) tells whenever he is happy or sad. That is, he tells me 'How I feel.' I can also share (the feeling) with him. When I am upset from work, I also share with him (the kid) too. (A father, Group 6, 302Z)

I communicate more with her (the mother). I tell her the happy and unhappy thins encountered in school. (A son, Group 6, 34C)

The participants reported that their family became more harmonious. There were fewer disputes and the participants knew how to get along with their family members. As the concepts of family $3 \mathrm{Hs}$ were interlocking, the happiness level also increased with a more harmonious family. Some participants became more aware of the importance of happiness and health as well.

(I) get along better with the elderly in our family. (Before the programs) I was not sure how the elderly thought. (Now, after the programs) I have an idea of 
how the elderly and kids think. (The family is) more harmonious. (A father, Group 4, 265A)

After participating in the activity, I think that happiness and health are the most important. (A wife, Group $1,282 \mathrm{~A})$

(The family is) more harmonious. That means there are fewer arguments. (The family is also) happier. (A father, Group 4, 265A)

\section{DISCUSSION}

Our intervention was effective in improving family communication and family well-being with a small effect size. Perceived communication adequacy substantially mediated the effect of intervention on perceived family $3 \mathrm{Hs}$. The quantitative measures were corroborated by the qualitative assessments which helped evaluate the outcomes more comprehensively.

Previous intervention programs using the social ecological model often contained multiple intensive sessions $(27,28)$. However, our resident training programs were very brief with only one core session and one booster session (total $5 \mathrm{~h}$ ). As expected, primary prevention interventions have small effects probably because of the low intensity of the intervention. However, these interventions are most useful when they can be disseminated to large numbers of people. From the public health point of view, brief interventions are expected to attract more participants, and enhance the feasibility and retention rate, as well as reduce the cost of training the interventionists and delivering the programs.

With the involvement of family members in our resident training programs such as workshops and interactive games, our intervention has shown effectiveness on improving family communication, family harmony, and family happiness. Possible reasons may be that these programs provided a platform for the participants to learn and communicate with family members as well as chat and share happy moments. They also learnt to discover and appreciate the strengths of their family members from the program activities.

Moreover, our study also adds to the literature by showing that family communication might be the pathway by which the intervention improved family well-being. The plausible explanation that perceived adequacy of family communication could determine family well-being is that family communication is closely related to the development of intimacy and closeness within families $(40,41)$, coping with stress and conflict $(42,43)$, as well as family problem solving and decision making $(44,45)$. However, communication time did not mediate the effect of intervention on family well-being possibly for several reasons. First, it may be difficult for the participants to recall communication time accurately, introducing random errors into measurement. Second, communication time does not necessarily indicate the quality of communication. Third, Hong Kong people have long working hours, and the small increase in family communication time may not be adequate to improve family well-being.

Our study has several limitations. First, although we chose two well-separated estates, we could not rule out contamination. Second, there were some differences between the intervention and control groups with regard to age and education because individual randomization was not practicable. However, we have adjusted for age and education when assessing the effectiveness of the intervention and the mediation effect of family communication. Third, loss of follow up in the intervention group at 6-week follow-up was about 30\%, larger than other studies with similar intensity of intervention in our FAMILY Project $(20,29)$. Future studies may consider some more appealing incentives to increase the retention rate. Fourth, there could also be some ceiling effects as some participants came with already high score in family well-being before the programs.

There is a Chinese saying that "harmony in family brings success to everything," reflecting the importance of family harmony in Chinese culture (46). This beneficial effect was substantially mediated by perceived adequacy of family communication. Further research and public education programs focusing on enhancing the quality of family communication are warranted. In addition, health and social service professionals working with families may emphasize the importance of family communication on family well-being to their clients.

Our community-based residents training programs based on the social ecological model improved family communication and perceived family harmony and happiness. Furthermore, perceived adequacy of family communication substantially mediated the effect of the intervention on family well-being, indicating that family communication might be a potential target for further intervention studies to promote family well-being.

\section{ETHICS STATEMENT}

Ethical approval was granted by the Institutional Review Board (IRB) of the University of Hong Kong/Hospital Authority Hong Kong West Cluster on November 2010. Written informed consent was obtained from all participants before the start of the programs. For participants younger than 15, written consent was obtained from the next of kin, caretakers, or guardians on their behalf.

\section{AUTHOR CONTRIBUTIONS}

CS led the development of this manuscript. SC, AW, LK, and TL contributed to the research design. SP and XW helped to collect data. CS analyzed the data. SS made continual input as the draft progressed and approved the final draft for submission. TL and SS critically reviewed the final draft. All authors read and approved the final manuscript.

\section{ACKNOWLEDGMENTS}

This study was part of the project entitled "FAMILY: A Jockey Club Initiative for a Harmonious Society," which was funded by The Hong Kong Jockey Club Charities Trust. Our sincere thanks must go to our community collaborators (the Christian Family Service Centre and the local organizations at Kwun Tong district in Hong Kong) and program participants. We are also grateful to our research team (Dr. Catalina Ng, Dr. David Wong, Ms. Cissy Soong, Mr. Paul Wong, Ms. Jenny Leung, Mr. Terence Li, Ms. Carmen Lung, and Ms. Wallis Lau) for their important contributions. 


\section{REFERENCES}

1. Pinquart M, Sörensen S. Influences of socioeconomic status, social network, and competence on subjective well-being in later life: a meta-analysis. Psychol Aging (2000) 15(2):187. doi:10.1037/0882-7974.15.2.187

2. Mason MJ, Schmidt C, Abraham A, Walker L, Tercyak K. Adolescents' social environment and depression: social networks, extracurricular activity, and family relationship influences. J Clin Psychol Med Settings (2009) 16(4):346-54. doi:10.1007/s10880-009-9169-4

3. Milevsky A, Schlechter M, Netter S, Keehn D. Maternal and paternal parenting styles in adolescents: associations with self-esteem, depression and life-satisfaction. J Child Fam Stud (2007) 16(1):39-47. doi:10.1007/s10826006-9066-5

4. Wickrama K, Lorenz FO, Wallace LE, Peiris L, Conger RD, Elder GH. Family influence on physical health during the middle years: the case of onset of hypertension. J Marriage Fam (2001) 63(2):527-39. doi:10.1111/j. 1741-3737.2001.00527.x

5. Meireles AL, Xavier CC, de Souza Andrade AC, Proietti FA, Caiaffa WT. Self-rated health among urban adolescents: the roles of age, gender, and their associated factors. PLoS One (2015) 10(7):e0132254. doi:10.1371/ journal.pone.0132254

6. Hwang K-K. Knowledge and Action: A Social-Psychological Interpretation of Chinese Cultural Tradition. Taipei: Sin-Li (1995).

7. Kwan VS, Bond MH, Singelis TM. Pancultural explanations for life satisfaction: adding relationship harmony to self-esteem. JPers Soc Psychol (1997) 73(5):1038. doi:10.1037/0022-3514.73.5.1038

8. Chuang YC. Effects of interaction pattern on family harmony and wellbeing: test of interpersonal theory, relational-models theory, and Confucian ethics. Asian J Soc Psychol (2005) 8(3):272-91. doi:10.1111/j.1467-839X.2005. 00174.x

9. Chan SS, Viswanath K, Au DW, Ma CM, Lam WW, Fielding R, et al. Hong Kong Chinese community leaders' perspectives on family health, happiness and harmony: a qualitative study. Health Educ Res (2011) 26(4): 664-74. doi:10.1093/her/cyr026

10. Lam WW, Fielding R, McDowell I, Johnston J, Chan S, Leung GM, et al. Perspectives on family health, happiness and harmony $(3 \mathrm{H})$ among Hong Kong Chinese people: a qualitative study. Health Educ Res (2012) 27(5):767-79. doi:10.1093/her/cys087

11. Pearson JC. Communication in the Family: Seeking Satisfaction in Changing Times. London, UK: Pearson College Division (1993).

12. Galvin KM, Tullos JM. Family Communication: Cohesion and Change. Will County, IL: Governors State University (1986).

13. Olson DH. Circumplex model of marital and family systems. J Fam Ther (2000) 22(2):144-67. doi:10.1111/1467-6427.00144

14. Karakas F, Dean Lee M, MacDermid SM. A qualitative investigation into the meaning of family well-being from the perspective of parttime professionals. Equal Oppor Int (2004) 23(1/2):57-77. doi:10.1108/ 02610150410787855

15. Yum JO. The impact of Confucianism on interpersonal relationships and communication patterns in East Asia. Commun Monogr (1988) 55(4): 374-88. doi:10.1080/03637758809376178

16. Chang H-C. Harmony as performance: the turbulence under Chinese interpersonal communication.DiscourseStud(2001)3(2):155-79. doi:10.1177/ 1461445601003002001

17. Hong Kong Social Welfare Department. Statistics on Elder Abuse Cases (2016). Available from: http://www.swd.gov.hk/en/index/site_pubsvc/page_family/ sub_listofserv/id_serabuseelder/

18. Hong Kong Social Welfare Department. Statistics on Child Abuse, Spouse/ Cohabitant Battering and Sex Violences Cases (2016). Available from: http:// www.swd.gov.hk/vs/english/stat.html

19. Leung GM, Ni MY, Wong PT, Lee PH, Chan BH, Stewart SM, et al. Cohort profile: FAMILY cohort. Int J Epidemiol (2017) 46(2):e1. doi:10.1093/ ije/dyu257

20. Fabrizio CS, Lam TH, Hirschmann MR, Pang I, Yu NX, Wang X, et al. Parental emotional management benefits family relationships: a randomized controlled trial in Hong Kong, China. Behav Res Ther (2015) 71:115-24. doi:10.1016/j.brat.2015.05.011

21. Yu X, Stewart SM, Chui JP, Ho JL, Li AC, Lam TH. A pilot randomized controlled trial to decrease adaptation difficulties in Chinese new immigrants to Hong Kong. Behav Ther (2014) 45(1):137-52. doi:10.1016/j.beth.2013. 10.003

22. Li WH, Mak YW, Chan SS, Chu AK, Lee EY, Lam TH. Effectiveness of a play-integrated primary one preparatory programme to enhance a smooth transition for children. J Health Psychol (2013) 18(1):10-25. doi:10.1177/ 1359105311434052

23. Soong CS, Wang MP, Mui M, Viswanath K, Lam TH, Chan SS. A "community fit" community-based participatory research program for family health, happiness, and harmony: design and implementation. JMIR Res Protoc (2015) 4(4):e126. doi:10.2196/resprot.4369

24. Stewart SM, Fabrizio CS, Hirschmann MR, Lam TH. Developing community-based preventive interventions in Hong Kong: a description of the first phase of the family project. BMC Public Health (2012) 12:106. doi:10.1186/1471-2458-12-106

25. McLaren L, Hawe P. Ecological perspectives in health research. J Epidemiol Community Health (2005) 59(1):6-14. doi:10.1136/jech.2003.018044

26. Sallis JF, Owen N, Fisher EB. Ecological models of health behavior. In: Glanz K, Rimer BK, Viswanath K, editors. Health Behavior and Health Education: Theory, Research, and Practice (Vol. 4). San Francisco, CA: Jossey-Bass (2008). p. $465-86$.

27. Powell E, Woodfield LA, Nevill AM. Increasing physical activity levels in primary school physical education: the SHARP principles model. Prev Med Rep (2016) 3:7-13. doi:10.1016/j.pmedr.2015.11.007

28. Peterson KE, Sorensen G, Pearson M, Hebert JR, Gottlieb BR, McCormick MC. Design of an intervention addressing multiple levels of influence on dietary and activity patterns of low-income, postpartum women. Health Educ Res (2002) 17(5):531-40. doi:10.1093/her/17.5.531

29. Fabrizio CS, Stewart SM, Ip AK, Lam TH. Enhancing the parent-child relationship: a Hong Kong community-based randomized controlled trial. J Fam Psychol (2014) 28(1):42. doi:10.1037/a0035275

30. Ho HC, Mui M, Wan A, Ng YL, Stewart SM, Yew C, et al. Happy family kitchen II: a cluster randomized controlled trial of a communitybased family intervention for enhancing family communication and wellbeing in Hong Kong. Front Psychol (2016) 7:638. doi:10.3389/fpsyg.2016.00638

31. Babcock JC, Waltz J, Jacobson NS, Gottman JM. Power and violence: the relation between communication patterns, power discrepancies, and domestic violence. JConsult Clin Psychol (1993) 61(1):40. doi:10.1037/0022-006X. 61.1.40

32. Papp LM, Kouros CD, Cummings EM. Demand-withdraw patterns in marital conflict in the home. Pers Relatsh (2009) 16(2):285-300. doi:10.1111/j. 1475-6811.2009.01223.x

33. Sanavi FS, Baghbanian A, Shovey MF, Ansari-Moghaddam A. A study on family communication pattern and parenting styles with quality of life in adolescent. J Pak Med Assoc (2013) 63(11):1393-8.

34. Wang MP, Chu JT, Viswanath K, Wan A, Lam TH, Chan SS. Using information and communication technologies for family communication and its association with family well-being in Hong Kong: FAMILY project. J Med Internet Res (2015) 17(8):e207. doi:10.2196/jmir.4722

35. MacKinnon DP, Fairchild AJ, Fritz MS. Mediation analysis. Annu Rev Psychol (2007) 58:593-614. doi:10.1146/annurev.psych.58.110405.085542

36. Introduction of Christian Family Service Centre (2017). Available from: http:// www.cfsc.org.hk/en/aboutUs

37. Cohen J. A power primer. Psychol Bull (1992) 112(1):155. doi:10.1037/ 0033-2909.112.1.155

38. Schafer JL. Multiple imputation: a primer. Stat Methods Med Res (1999) 8(1):3-15. doi:10.1177/096228029900800102

39. Braun V, Clarke V. Using thematic analysis in psychology. Qual Res Psychol (2006) 3(2):77-101. doi:10.1191/1478088706qp063oa

40. Koerner AF, Fitzpatrick MA. Toward a theory of family communication. Commun Theory (2002) 12(1):70-91. doi:10.1111/j.1468-2885.2002.tb00260.x

41. Samek DR, Rueter MA. Associations between family communication patterns, sibling closeness, and adoptive status. J Marriage Fam (2011) 73(5):1015-31. doi:10.1111/j.1741-3737.2011.00865.x

42. Sillars A, Canary DJ, Tafoya M. Communication, conflict, and the quality of family relationships. In: Vangelisti AL, editor. Handbook of Family Communication. Mahwah, NJ: Lawrence Erlbaum Associates, Inc (2004). p. 413-46.

43. Olson DH, Dreman S. Family stress and coping: a multisystem perspective. In: Dreman S, editor. The Family on the Threshold of the 21st Century: Trends 
and Implications. Mahwah, NJ: Lawrence Erlbaum Associates, Inc (1997). p. 259-80.

44. DeLambo KE, Ievers-Landis CE, Drotar D, Quittner AL. Association of observed family relationship quality and problem-solving skills with treatment adherence in older children and adolescents with cystic fibrosis. J Pediatr Psychol (2004) 29(5):343-53. doi:10.1093/jpepsy/ jsh038

45. Bakir A, Rose GM, Shoham A. Family communication patterns: mothers' and fathers' communication style and children's perceived influence in family decision making. J Int Consum Mark (2006) 19(2):75-95. doi:10.1300/ J046v19n02_05

46. Lau S, Lew WJ, Hau K-T, Cheung PC, Berndt TJ. Relations among perceived parental control, warmth, indulgence, and family harmony of Chinese in mainland China. Dev Psychol (1990) 26(4):674. doi:10.1037/0012-1649. 26.4.674

Conflict of Interest Statement: The authors declare that the research was conducted in the absence of any commercial or financial relationships that could be construed as a potential conflict of interest.

Copyright $\odot 2017$ Shen, Wan, Kwok, Pang, Wang, Stewart, Lam and Chan. This is an open-access article distributed under the terms of the Creative Commons Attribution License (CC BY). The use, distribution or reproduction in other forums is permitted, provided the original author(s) or licensor are credited and that the original publication in this journal is cited, in accordance with accepted academic practice. No use, distribution or reproduction is permitted which does not comply with these terms. 